\title{
Hamit Bozarslan, Le luxe et la violence. Domination et contestation chez Ibn Khaldûn
}

Paris, CNRS Éditions, 2014, 240 p.

Bibliographie, glossaire, index.

\section{Mustapha Naïmi}

\section{(2) OpenEdition}

Journals

Édition électronique

URL : http://journals.openedition.org/assr/26344

DOI : $10.4000 /$ assr. 26344

ISSN : 1777-5825

Éditeur

Éditions de l'EHESS

Édition imprimée

Date de publication : 31 décembre 2014

Pagination : 154

ISBN : 978-2-7132-2467-6

ISSN : 0335-5985

Référence électronique

Mustapha Naïmi, «Hamit Bozarslan, Le luxe et la violence. Domination et contestation chez Ibn Khaldûn », Archives de sciences sociales des religions [En ligne], 168 | 2014, mis en ligne le 08 avril 2015, consulté le 22 septembre 2020. URL : http://journals.openedition.org/assr/26344 ; DOI : https:// doi.org/10.4000/assr.26344

Ce document a été généré automatiquement le 22 septembre 2020.

(c) Archives de sciences sociales des religions 


\section{Hamit Bozarslan, Le luxe et la violence. Domination et contestation chez Ibn Khaldûn}

Paris, CNRS Éditions, 2014, 240 p.

Bibliographie, glossaire, index.

Mustapha Naïmi

\section{RÉFÉRENCE}

Hamit Bozarslan, Le luxe et la violence. Domination et contestation chez Ibn Khaldûn, Paris, CNRS Éditions, 2014, 240 p.

Bibliographie, glossaire, index. 
1 L'auteur relit l'œuvre d'Ibn Khaldûn, cet historien du XIV siècle et théoricien de la civilisation, en reliant sa mise en évidence de cycles et de contradictions due à l'inévitable routinisation du pouvoir qui mène à la décadence et à l'actualité contemporaine (la chute du régime de Ben Ali en Tunisie, Moubarak en Égypte).

2 L'auteur considère que la conceptualisation chez Ibn Khaldûn, penseur d'État, qui pense ce concept à partir d'une posture conservatrice, sert à interroger l'État dans ses contradictions et ses crises. Dans la violence dont il est, de manière structurelle, le produit et le producteur, dans son discours juridique qui glorifie sa violence fondatrice sans se permettre d'échapper à celle, destructrice, qu'il engendre par ses actes, dans la fatalité qui constitue son horizon ultime y compris dans sa chute, il nous montre aussi que la pensée conservatrice a quelque chose de proprement révolutionnaire à nous offrir.

3 L'auteur obéit à une véritable quête de cohérence et de sens. Autant les exemples historiques foisonnent dans son récit, autant les concepts-clefs qu'il mobilise sont limités à une vingtaine (civilisation, clan, pouvoir, domination, tyrannie, 'assabyya, da 'wa, obéissance, taxation, imposition, luxe). Ce fait n'est ni fortuit, ni spécifique à son œuvre. Selon Émile Benveniste, «toute l'histoire de la pensée moderne et les principaux achèvements de la culture intellectuelle dans le monde occidental sont liés à la création et au maniement de quelques dizaines de mots essentiels ". Il en va de même du monde musulman. La particularité des concepts-clefs khaldouniens, tout comme ceux venant d'autres temps et d'autres lieux, réside dans le fait qu'ils sont « éternels »; polysémiques, et donc inévitablement ambigus, ils sont susceptibles de provoquer des querelles d'interprétation et peuvent s'avérer, dans une dialectique de continuité et de tension, " associables » les uns aux autres, ou à l'inverse s'opposer entre eux comme autant d'outils décrivant des processus contradictoires mais observés simultanément ou successivement sur plus d'un terrain.

4 Chez Ibn Khaldûn, le pouvoir (mulk) est défini « comme [un] concept général désignant l'exercice de l'autorité par la contrainte et la domination, et comme forme concrète d'exercice de la souveraineté dans un contexte social et politique déterminé ». Il n'est donc pas une structure, une permanence dont on postule qu'Ibn Khaldûn les a multipliées dans sa conception supposée cyclique. C'est au contraire un temps de déséquilibre créateur, comme la formation de la 'assabyya bédouine elle-même. " Le mulk n'est pas seulement le pouvoir, c'est la prise ou la fondation du pouvoir, né bédouin, sur un espace sédentaire ».

5 L'auteur voit là une association entre le pouvoir comme donne première, constitutive, en tant que nœud symbolique d'un ensemble de rapports, d'institutions et de sens, un « fait social total » tel que Marcel Mauss définit le terme. Ibn Khaldûn est on ne peut plus clair à ce sujet : il est voulu par Dieu comme condition de l'existence de la société, mais il n'a besoin ni de la religion révélée ni de la prophétie pour exister.

6 Schizophrénique, le pouvoir a une pratique radicalement opposée à sa théorie, qu'il ne saurait pourtant abandonner sans prendre le risque de périr: dans la pratique, il se démultiplie et se partage à tous les échelons, mais dans la théorie, il ne peut se diviser sans compromettre sa "capacité d'exercer le commandement ». Ibn Khaldûn fait une extrapolation tout à fait audacieuse du verset XXI-22 du Coran : «Si dans le ciel et la terre il y avait des divinités autres que Dieu, elles seraient détruites ", dès lors «la politique exige que l'autorité soit exercée par un seul. Si elle était partagée entre 
plusieurs, cela entraînerait la ruine de l'ensemble ». Cette démonstration à partir d'une théologie cosmique est aussi clairement une invitation à la prudence quant à la traduction du terme, polysémique, de siyasa. Assurément, la siyasa signifie «s'emparer du pouvoir ", exercer le pouvoir, "s'occuper des affaires publiques", qui n'est pas synonyme de «politique » comme on l'interprète souvent. Elle est un principe d'unité et d'efficacité, non de conflits légitimés et négociés à partir d'un ensemble de règles admises par la cité, qui paraissent en général comme consubstantiels à la " politique ».

Cette situation inconfortable, opposant radicalement une doctrine et un idéal d'État pourtant intimement liés, s'alourdit davantage dans le monde musulman du tournant du deuxième millénaire. D'un côté, les légistes ont élaboré, bien avant l'époque d'Ibn Khaldûn, une théorie extrêmement sophistiquée, souple et contraignante à la fois, qui légitime tout État établi à condition qu'il appartienne à l'Islam entendu comme communauté ; de l'autre côté, l'idéal du califat juste, aux antipodes de cette doctrine, est plus que jamais mis en exergue, souvent d'ailleurs par les mêmes légistes.

L'auteur procède à une longue digression sur la comparaison entre Ibn Khaldûn et Pareto, sociologue du début $\mathrm{du} \mathrm{xx}^{\mathrm{e}}$ siècle, qui voit dans la circulation des élites le véritable moteur de l'histoire. Comme Ibn Khaldûn, Pareto est impressionné par la double nature du pouvoir : pérenne comme principe, il est fragile et constamment au bord du gouffre comme règne donné. Méfiant par rapport aux promesses du progrès, très attentif aux actions régulées et "pures ", il se heurte sans cesse, comme Ibn Khaldûn, aux actions apparemment non logiques, qui invalident son modèle.

Ibn Khaldûn avait une vision aussi claire que déchirée de ce qu'étaient les Arabes et de ce qu'ils étaient devenus. Il n'était pas le premier. La conscience de l'arabité est présente depuis l'époque du prophète, puisque dès ce moment on parle d'ard al-arab, jazirath al-arab, mulk al-arab. À l'évidence, ces définitions ne renvoient plus, du moins plus exclusivement aux groupes tribaux, mais désignent bien un groupe ethnique, groupe de pouvoir se concevant comme supérieur aux autres. L'ampleur des traités «médiévaux » sur la langue arabe, qui s'impose rapidement en vecteur de la seule culture et de la religion, en atteste.

Il reste que le seul penseur à permettre une comparaison avec Ibn Khaldûn sur le thème de l'état de barbarie, civilisation rustre, est Arnold Toynbee. Il a également une vision assez originale de la barbarie, terme entendu au sens antique, c'est-à-dire les marges de l'Empire. Comme Ibn Khaldûn, Toynbee se pose la question de la formation des marges ; mais pour lui, deux forces, l'une interne mais pacifique que l'auteur définit dans une terminologie khaldounienne, porteuse d'une da'wa, l'autre externe mais forte d'une puissance militaire, une sorte d'assabiyya, convergent pour détruire un ordre existant. Convergence et non entente : la distinction est importante, mais uniquement dans une première phase. Rapidement s'opère une fusion entre les deux : la christianisation des barbares permet de renforcer leur assabiyya par la da'wa et dote en retour la da'wa religieuse des structures de solidarité et de cohésion dont elle a besoin. 